\title{
Protective effect of rutin against high glucose-induced oxidative damage in PC12 cells
}

\author{
Wan-Zhong Li ${ }^{* a}$, Chun-Zhen Zhao and Jin-Bao Zhang ${ }^{c}$ \\ ${ }^{a}$ Department of Pharmaceutics and Applied Pharmacology Laboratory, Weifang Medical University, \\ Weifang, China, \\ ${ }^{b}$ Department of Pharmacology and Applied Pharmacology Laboratory, Weifang Medical University, \\ Weifang, China, \\ 'Department of genetics and Applied Pharmacology Laboratory, Weifang Medical University, \\ Weifang, China。. \\ aemail:wanzhongli@hotmail.com, bemail:chunzh414@163.com, email:zhjbdcm1999@163.com
}

Keywords: Rutin, High glucose, Oxidative damage, Nitric oxide synthase, Nitric oxide

\begin{abstract}
Objective: This study evaluated the protective effect of rutin on high glucose-induced damage in PC12 cells. Methods: Viability of PC12 cells induced by high glucose was detected by MTT assay and cell death by lactate dehydrogenase release. Nucleic acid status in the cell was observed by Hoechst 33342 staining. NO and NOS were measured using detection assay kits. Results: PC12 cells were pretreated with various concentrations of rutin for $1 \mathrm{~h}$ and then coped with rutin and D-glucose for $48 \mathrm{~h}$. Rutin protected PC12 cells against high glucose damage, which was determined by cell viability and apoptosis as evaluated by Hoechst 33342 staining assay. Rutin inhibited increased NOS activity in a concentration-dependent manner. Increased NO level was significantly reduced by rutin. Conclusions: Findings revealed the protective effect of rutin against high glucose-induced oxidative damage in PC12 cells. Results suggest that rutin could be a potentially natural compound for diabetic neuropathy treatment.
\end{abstract}

\section{Introduction}

Diabetes mellitus(DM) is characterized by the failure of the pancreas to secrete sufficient insulin to maintain physiological levels of blood glucose. Diabetic neuropathy(DN) is among the most common long-term complications of DM[1], This complication is the main cause of chronic disability in diabetic patients. DN is a serious consequence of long-term intracellular glucose metabolism that leads to neuronal damage, resulting in neuronal complications of diabetes.Evidence has clarified the relationship between diabetes and neurodegenerative disorders[2,3].

It's well known that apoptosis has been regarded as possible mechanism for high glucose-induced neuronal dysfunction and cell death in both in vitro and in vivo studies[4]. Under hyperglycemic conditions, free radicals such as nitric oxide(NO) and reactive oxygen species(ROS), contributed to the oxidative stress(OS) and neuronal apoptosis increased[5]. Hyperglycemia causes DN by a mechanism which involves generation of nitric oxide synthase(NOS) and alterations.

It has been suggested that antioxidant and free radical scavenging activities of flavonoids are involved in the inhibition of enzymes of oxygen-reduction pathways and modulation of protein signalling pathways[6]. Rutin has been suggested its potential as neuroprotective substance in the nervous system. In the present study, the possible neuroprotective effect of rutin was investigated in high glucose -treated PC12 cells as in vitro model of DN. 


\section{Materials and methods}

Materials. Rutin was purchased from National Institute for Food and Drug Control (Beijing, China). MTT [3-(4,5) -dimethylthiahiazo (-zy-1)-3,5-di-phenytetrazoliumromide] and Hoechst 33342 were purchased from Sigma-Aldrich. PMI 1640 were purchased from Hyclone (Thermo scientific, USA). Fetal bovine serum (FBS) was purchased from Sijiqing (Hangzhou, China). LDH (lactate dehydrogenase) kit, NO metabolite detection kit and NOS detection assay kit were purchased from Nanjing Jiancheng Bioengineering Institute (Nanjing, China).

Cell Culture and Treatment. To produce hyperglycemia, the high differentiated PC12 cells were treated with D-(+)-glucose at different concentrations $(25,50,75,100,150,300 \mathrm{mM})$ for 24 and $48 \mathrm{~h}$. After the cells were pretreated with D-glucose $(100 \mathrm{mM})$ for $1 \mathrm{~h}$, then co-treated with rutin and D-glucose for continuous $48 \mathrm{~h}$. Control cells were cultured normally, and not treated with rutin. The final rutin concentation of dimethyl sulfoxide (DMSO) and PBS was less than $0.1 \%(\mathrm{v} / \mathrm{v})$. Each independent experiment was carried out more than three times.

Cell Viability Analysis. The cells were seeded onto 96-well culture plates at 5000 cells/well and cell viability was assessed by a modified MTT reduction assay. LDH activity was detected by the appropriate kit in cell cultured medium. After glucose treatment in the absence or presence of rutin, $10 \mu \mathrm{l}$ of MTT $(5 \mathrm{mg} / \mathrm{ml})$ solution was added to the cultured media $(100 \mu \mathrm{l})$ at a final concentration of $0.5 \mathrm{mg} / \mathrm{ml}$. The cells were incubated at $37^{\circ} \mathrm{C}$ for $4 \mathrm{~h}$. Then the media were removed carefully and $100 \mu \mathrm{l}$ of dimethyl sulfoxide was added to each well. The absorption was determined at $570 \mathrm{~nm}$ by an ELISA reader. Results are expressed as percentages of control group.

Hoechst 33342 Staining. PC12 cells were seeded in the 24 -well plates at $3 \times 105 /$ well and treated with Hoechst 33342 fluorochrome $(10 \mu \mathrm{g} / \mathrm{ml})$ for $10 \mathrm{~min}$ at $37^{\circ} \mathrm{C}$. The cells were fixed in cold methanol $\left(-20^{\circ} \mathrm{C}\right)$. Then the stained cells were observed under a fluorescence microscope. The apoptotic cells were determined as condensed nuclei with strong bright Hoechst 33342 staining. A total of 200 cells from five random fields were counted and the percent of apoptotic cells were expressed as percentages of total cells.

NO and NOS assay. After glucose $(100 \mathrm{mM})$ and drug treatment for $48 \mathrm{~h}$, the supernatant was collected. NO generated by cells was quantified by measuring nitrate and nitrite in the culture media with detect assay kit. NOS was measured using activity assay kit. All the procedures were operated strictly according to manufacturer's protocals.

Statistical Analysis. Data are expressed as means \pm SEM. The differences were analyzed by one-way ANOVA followed by the Newman-Keuls test. P $<0.05$ was considered to be statistically significant.

\section{Results}

Effect of Glucose on PC12 Cell Viability. The effects of different concentrations of glucose on PC12 cells viability were evaluated by MTT assay. After the initial grow period, the cells were exposed to glucose at the concentration of 25, 50, 75, 100, 150, $300 \mathrm{mM}$ for 24 and $48 \mathrm{~h}$. MTT assay showed that glucose could decreased the viability of PC12 cells in a concentration-dependent manner after 24 and $48 \mathrm{~h}$ (refer with: Fig. 1A and 1B). This damage was time-dependently increased, so the concentration was selected to induce cell injury and evaluate the protective effect of rutin. 

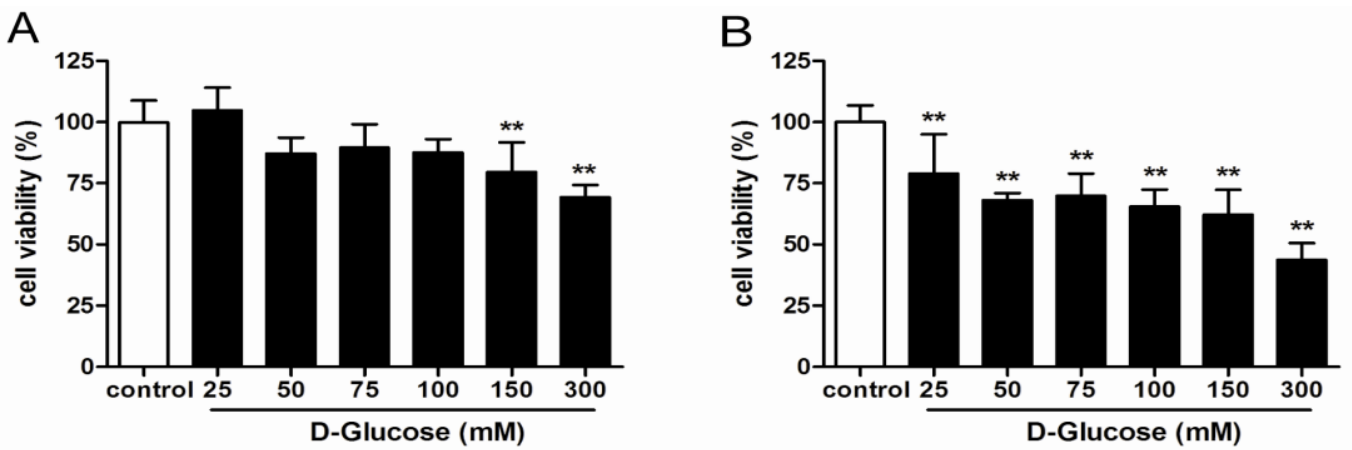

Figure. 1 Effect of glucose on PC12 cell viability for $24 \mathrm{~h}(\mathrm{~A})$ and $48 \mathrm{~h}(\mathrm{~B})$ incubation(n=8). ${ }^{* *} P<0.01$ compared to the control group.

Effect of Rutin on High Glucose-induced Cell Damage. To elucidate the neuroprotective effect of rutin in vitro, we study the effect of rutin on PC12 cells with high glucose treatment (refer with: Fig. $2 \mathrm{~A}$ and $2 \mathrm{~B})$.Glucose $(100 \mathrm{mM})$ for $48 \mathrm{~h}$ reduced PC12 cells viability, pretreatment of rutin at $0.001 \sim 10 \mu \mathrm{M}$ concentration-dependently prevented the damage induced by high glucose. No injury effect was found on normal medium-incubated cells, treated with rutin at concentrations of 0.001 10 $\mu \mathrm{M}$.
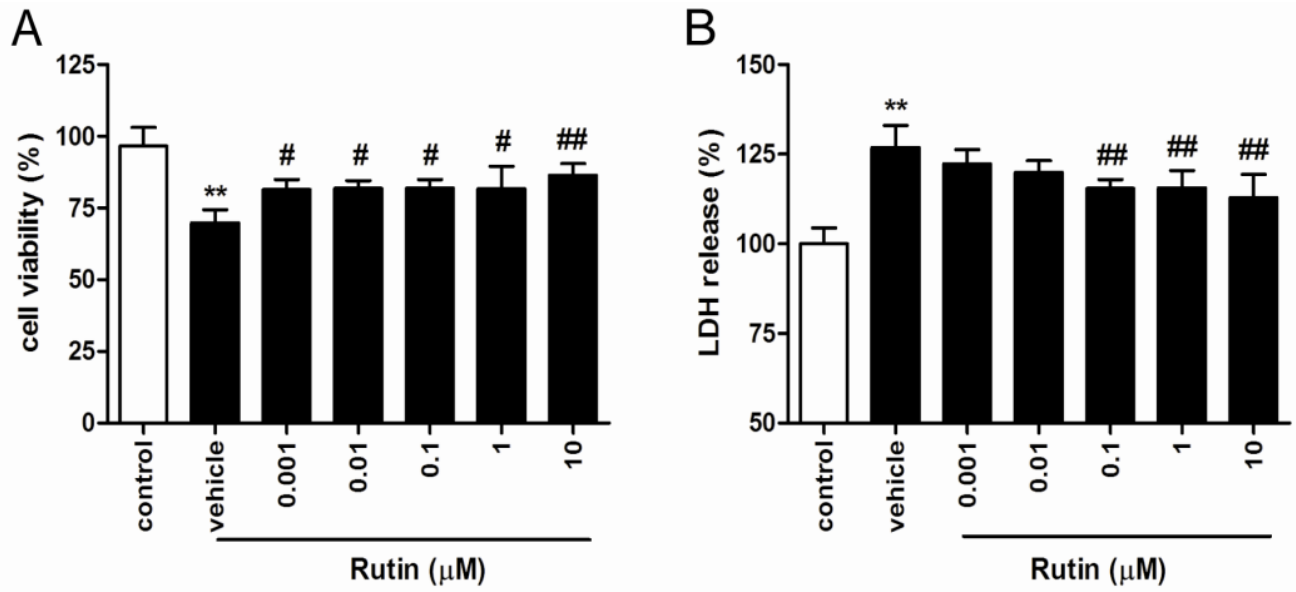

Figure. 2 Effect of Rutin on high glucose-induced cell viability and LDH release in PC12 cells(n=6). ${ }^{* *} P<0.01$ compared to control group. ${ }^{\#} P<0.05,{ }^{\# \#} P<0.01$ compared to vehicle group.

Rutin Inhibited High Glucose-induced Apoptosis. To examine whether rutin protect PC12 cells from high glucose induced apoptosis, we study the effect of rutin on HG-induced cultured PC12 cells apoptosis stained by Hoechst 33342.

Exposure to high glucose $(100 \mathrm{mM})$ for $48 \mathrm{~h}$ increased the ratio of apoptotic cells with cell shrinkage, chromatin condensation, and strong bright fluorescent nuclei (refer with: Fig. 3A). The ratio of apoptotic cells was significantly reduced by rutin concentrations of $0.001 \sim 10 \mu \mathrm{M}$ (refer with: Fig. 3 B). Vehicle group (DMSO $0.1 \%$ ) had no effect on apoptosis of PC12 cells under the condition of high glucose. 

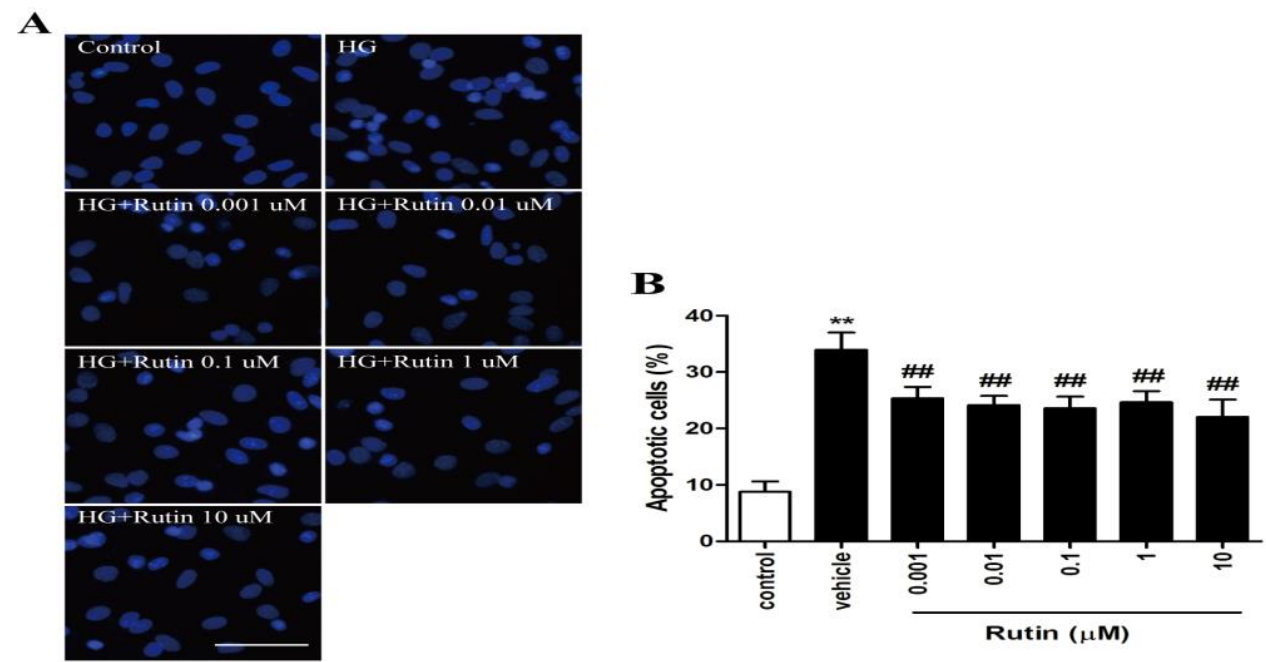

Figure. 3 Rutin reduced high glucose-induced apoptosis in PC12 cells $(n=8){ }^{* *} P<0.01$ versus control group. ${ }^{\#} P<0.05,{ }^{\# \#} P<0.01$ versus vehicle group.

Rutin Reduced High Glucose-induced NO Release and NOS Activity. We found that increased NO level induced by $100 \mathrm{mM}$ glucose for $48 \mathrm{~h}$ was reduced by pretreatment with rutin $(0.01 \sim 10 \mu \mathrm{M})$ in a concentration-dependent manner(refer with: Fig. 4A). NOS activity was significantly increased in the high glucose-treated PC12 cells as compared to control medium. Rutin $(0.01 \sim 10 \mu \mathrm{M})$ significantly inhibited NOS activity induced by high glucose compared to vehicle group(refer with: Fig. 4B). Rutin $(0.001 \mu \mathrm{M})$ or Vehicle group had no effect on NOS activity of PC12 cells under the condition of high glucose.
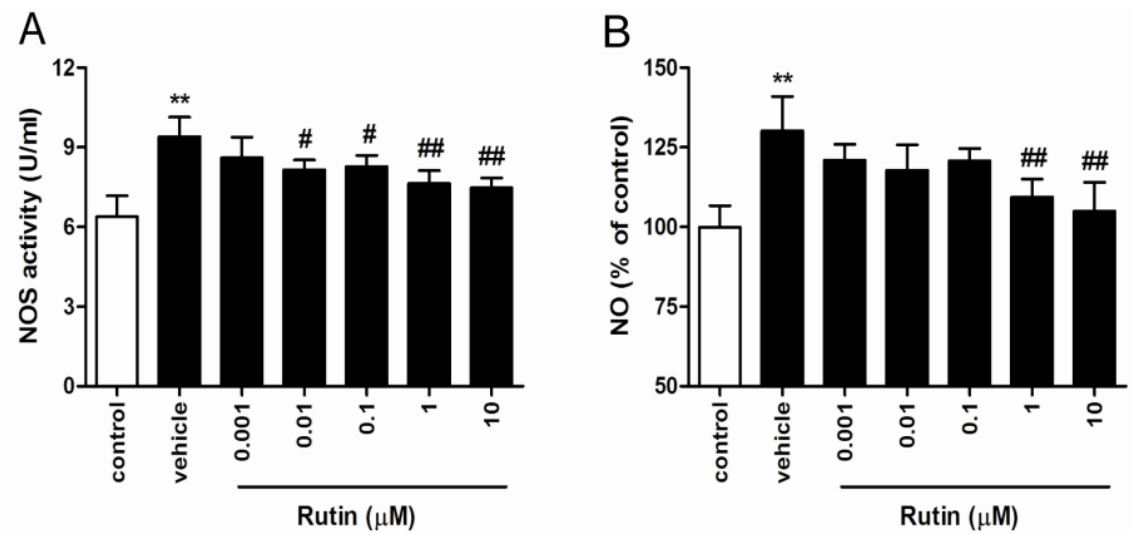

Figure. 4 Effect of Rutin on NOS activity and NO levels in the medium of PC12 cells induced by high glucose(n=6). ${ }^{* *} P<0.01$ compared to control group. ${ }^{\#} P<0.05,{ }^{\# \#} P<0.01$ compared to vehicle group.

\section{Discussion}

DN is one of the most common and serious complications of DM. Much evidence indicated that hyperglycemia played a key role in the development and progression of DN[7]. Hyperglycemia induces oxidative stress to generate reactive oxygen species and reactive nitrogen species in diabetic neurons resulting in neuronal damage and dysfuntion. Hyperglycemia induces apoptosis in primary neurons by increasing the production of reactive oxygen species. We found that high glucose reduced cell viability and increased damage in high differentiated PC12 neuronal cells[8].

The results taken together suggest protective effect of rutin on glucose damage in PC12 cells was mediated by NO. High glucose induced damage in PC12 cells through NOS activation to product nitric oxide[9].Rutin has antioxidative and antiinflammatory properties[10]. The present study demonstrated 
that inhibitory effect of rutin on high glucose-induced cell injury and apoptosis in PC12 neural cells is related to inhibition of NOS activation and NO production. Rutin might protect the cell membrane from high glucose -induced damage.

Rutin was reported as a potent antioxidant and may help to enhance the status of endogenous antioxidant systems, and may protect from oxidative damage[11].More cellular and molecular studies will be needed to unravel the key roles of rutin as preventive and complementary stategies for DN. Further understanding the mechanism underlying the neuroprotection of rutin will provide an avenue to disclose both the pathogenesis and therapeutic mechanisms underlying DN. We should be able to develop strategies for a more rational treatment of DN.

\section{Conclusions}

This study demonstrates a correlation between glucose concentration and severity of the damage to the PC12 cells. The current research revealed that protective effect of rutin against high glucose-induced cell damage in PC12 cells. These results suggest rutin could be a potentially natural compound in DN treatment.

\section{Acknowledgements}

This work was supported by the National Natural Science Foundation of China (81274049 and 81341137), Scientific Foundation of Shandong Province (2012CQ039).

\section{References}

[1] Rajabally YA.: Acta Neurol Scand, Vol.124(2011), p.1-8.

[2] Vignini A, Giulietti A, Nanetti L, Raffaelli F, Giusti L, Mazzanti L, ProvincialiL: Curr Diabetes Rev, Vol.9 (2013)No. 3, p.218-27.

[3] Jagota P, Bhidayasiri R, Lang AE: J Neurol Sci, Vol.314 (2012), p. 5-11.

[4] Xu X, Jiang H, Liu H, Zhang W, Xu X, Li Z: Brain Res Bull, Vol.87 (2012) No. (1), p. 85-93.

[5] Renaud J, Bournival J, Zottig X, Martinoli MG: Neurotox Res, Vol.25 (2014) No. 1, p.110-123.

[6] Jader Nones, Ana Paula Costa, Rodrigo Bainy Leal, Flavia Carvalho Alcantara Gomes, Andrea Gonçalves Trentin: Cell and Tissue Research, Vol.350 (2012) No. 2, p. 305-315.

[7]Afrazi S1, Esmaeili-Mahani S, Sheibani V, Abbasnejad M: J Steroid Biochem Mol Biol, Vol.139(2014), p.98-103.

[8] Zhao CZ, Zhao B, Zhang XY, Huang XQ, Shi WZ, Liu HL, Fang SH, Lu YB, Zhang WP, Tang FD, Wei EQ: Neuroscience, Vol.189 (2011), p.1-11.

[9] Koshimura K, Tanaka J, Murakami Y, Kato Y: Neurosci Res, Vol.43 (2002) No. 1, p. 31-38.

[10] Mohd. Moshahid Khan, Syed Shadab Raza, Hayate Javed, Ajmal Ahmad, Andleeb Khan, Farah Islam, Mohammed M. Safhi, Fakhrul Islam: Neurotox Res, Vol.22(2012), p.1-15.

[11] Khan MM, Ahmad A, Ishrat T, Khuwaja G, Srivastawa P, Khan MB, Raza SS, Javed H, Vaibhav K, Khan A, Islam F: Brain Res, Vol.1292(2009), p. 123-135. 